\title{
Root proteome alterations in sugarcane promoted by the regrowth cycle in commercial production
}

\author{
Rone Charles Maranho1, Mariana Mancini Benez², Gustavo Barizon Maranho², Eduardo Jorge Pilau ${ }^{3}$, \\ Claudete Aparecida Mangolin ${ }^{4}$, Maria de Fátima P. S. Machado ${ }^{4^{*}}$
}

\author{
${ }^{1}$ Postdoctoral in Agronomy, ${ }^{2}$ Graduate student in the Agronomy, ${ }^{3}$ Department of Chemistry, ${ }^{4}$ Department \\ of Biotechnology, Genetics and Cell Biology, Universidade Estadual de Maringá, Maringá, PR 87020-900, \\ Brazil
}

\section{*Corresponding author: mfpsmachado@uem.br}

\begin{abstract}
The decrease in agricultural productivity in successive cutting of sugarcane plants is associated with several extrinsic and intrinsic factors. However, no studies have focused on the physiological potential of sett roots in successive cuts in sugarcane culture. There have been no proteomic studies on sugarcane sett roots at different stages of cutting. In this study, the UPLC-ESI-TOF-MS system and bioinformatics tools were used to identify proteins of sett roots in the first and fifth cuts of sugarcane cultivar RB966928 in the sprouting stage. Differences in the proteome of sett roots of RB966928 in the first and fifth cuts detected in this study supports the hypothesis that the proteome of sett roots may change after successive cuts in sugarcane culture. A reduction in the number of proteins was observed in the roots of the fifth cut, whereas $34 \%$ of proteins, identified exclusively in the first cut, were absent in the fifth cut. Proteome analysis of sett roots in the first and fifth cuts showed that the changes after successive cuts were quantitative (number of proteins) and mainly qualitative. In this study, the detailed list of proteins identified in the first cut but absent in the fifth cut is relevant. The findings of this study may aid further research that employ biotic or abiotic elicitors to induce gene expression of essential proteins absent in sett roots of the fifth cut, and thus increasing the agricultural productivity and longevity of cane fields.
\end{abstract}

Keywords: Saccharum spp.; longevity; productivity; stress proteins; sett roots proteomic.

Abbreviations: 1D SDS-PAGE_one dimensional sodium dodecyl sulfate polyacrylamide gel electrophoresis; LC-MS/MS_liquid chromatography coupled with sequential mass spectrometry; PPI_protein-protein interaction network; UPLC-ESI-TOF-MS_ultra performance liquid chromatography-electrospray ionization-time of flight-mass spectrometer.

\section{Introduction}

Sugarcane (Saccharum spp.) is used for the production of alcohol and sugar worldwide. In addition, the pharmaceutical, cosmetic, and chemical industries are benefited from sugarcane byproducts for the manufacture of various materials and chemical components. Commercial sugarcane is a ratoon crop (Plucknett et al., 1970) depending on the sprouting of axillary buds present in seed-pieces (Ming et al., 2006). An economically viable sugarcane field depends on the high rates of axillary bud sprouting during harvest. Thus, the longevity of the cane field, approximately five cuts for most cultivars in Brazil (Santos and Borém, 2013), is a determining factor for the success of the culture.

The sprouting of axillary buds in the stem after harvesting is accompanied by forming a root group called sett roots (Glover, 1967; Moore and Botha, 2014). The sett roots are formed in a band of root primordium above the leaf scar at the culm nodes (Van Dillewijn, 1952; Glover, 1967). The sett roots are used for anchoring and sustaining the new sprout, and for soil-plant interaction at the start of axillary bud sprouting (Smith et al., 2005). Sett roots remain for approximately 10 weeks (cultivar-dependent) after sprouting, and thereafter replaced by shoot roots (Spaull, 1990).
Budding is essential for generating vigorous plants for the next sugarcane production cycle (longevity).

The decrease in agricultural productivity in successive cuttings has been related to several extrinsic and intrinsic factors (Manhães et al., 2015). However, to date, no studies have assessed the physiological potential of sett roots in successive cuts in sugarcane culture. Changes in gene expression of the axillary buds at the fifth cut have been detected in sugarcane cultivars (Benez et al., 2019; Maranho et al., 2019) and may or may not be observed in sett roots after successive cuts. Proteome analysis revealed a reduction of proteins in the axillary buds of the fifth cut in the RB867515 sugarcane cultivar (Maranho et al., 2019). However, there have been no proteomic studies on sugarcane sett roots at different cut stages.

This study hypothesizes that the proteome of sett roots may change after successive cuts in sugarcane culture. This study elucidates the physiological role of sett roots in sugarcane and identifies genes involved in the synthesis of proteins essential for the stability and maintenance of average agricultural productivity in sugarcane fields. The UPLC-ESI-TOF-MS system and bioinformatics tools were used to identify proteins of sett 
roots in the first and fifth cuts of the sugarcane cultivar RB966928 in the sprouting stage.

\section{Results}

\section{Root proteome of cultivar RB866928}

The complex protein mixture by the TCA/acetone modified method quantified concentrations of $621 \mu \mathrm{g} \mathrm{mL}^{-1}$ in the sett roots of the first cut and concentrations of $924 \mu \mathrm{g} \mathrm{mL}^{-1}$ in the fifth cut sett roots. Pre-fractionation by 1D SDS-PAGE demonstrated good quality extraction (Figure 1), with protein bands ranging from approximately $120 \mathrm{kDa}$ to $22 \mathrm{kDa}$.

The sett root proteome was compounded with 141 proteins, of which 125 and 93 proteins were detected in the first and fifth cuts, respectively. Forty-eight proteins (34.04\% of total proteome) were exclusively detected in the first cut (Table S1, marking - Supplementary material), while only 16 proteins (11.34\% of total proteome) were exclusively detected in the fifth cut (Table S2, marking - Supplementary material). Seventy-seven proteins were identified at both the cutting ages.

Proteins identified in the sugarcane sett roots of cultivar RB966928 integrate several diverse cellular processes and components. They are involved in carbon metabolism, lipid metabolism, protein metabolism, response to biotic and abiotic stresses, transcription factors, ribosomal components, and elongation factor, among others.

\section{Differential proteome of first and fifth cut sett roots}

The 48 proteins differentially identified in the sett roots of first cut seed-pieces, participate in several cellular functions, acting as enzymes, structural proteins, or as proteins and/or polypeptides, regulating transcription and gene regulation. A group of proteins related to the chaperone family was evident in the proteome of the sett roots during the first cutting. Six heat shock proteins (heat shock cognate $70 \mathrm{kDa}$ protein 2 , heat shock cognate $70 \mathrm{kDa}$ protein 1 , heat shock cognate $70 \mathrm{kDa}$ protein 3 , heat shock cognate protein 80 , heat shock protein 90-2, and heat shock protein 82), two chaperonins (chaperonin CPN60-2, mitochondrial precursor, $20 \mathrm{kDa}$ chaperonin, chloroplast precursor), 2 luminal binding proteins (luminal binding protein 5 precursor, luminal binding protein 4 precursor), the chloroplast envelope membrane 70 $\mathrm{kDa}$ (chloroplast envelope membrane $70 \mathrm{kDa}$ heat shockrelated protein), and two Rubisco subunit binding-protein (RuBisCO subunit binding-protein beta subunit, RuBisCO subunit binding-protein alpha subunit, chloroplastic) are given in Table S1. Some of these proteins (RuBisCO subunit binding-protein beta subunit, luminal binding protein 5 , heat shock cognate $70 \mathrm{kDa}$ protein 2 , heat shock cognate protein 80 , heat shock cognate $70 \mathrm{kDa}$ protein 1 , heat shock protein $90-2$, heat shock cognate $70 \mathrm{kDa}$ protein 3 , chaperonin CPN60-2 mitochondrial precursor, and $20 \mathrm{kDa}$ chaperonin chloroplast precursor) may be observed in Figure 2A (red marking), where the analysis of the PPI network revealed the presence of interactions between them, indicating a biological connection.

Proteins related to stress responses and root growth and development have also been identified only in the sett roots of the first cutting, such as phosphoglucomutase, cytoplasmic 1 (EC 3.1.4.4), pyruvate dehydrogenase E1 component beta subunit, mitochondrial (EC 1.2.4.1), phospholipase D 1 precursor (EC 3.1.4.4), and 1-aminocyclopropane-1- carboxylate oxidase (EC 1.14.17.4). Tables 1 and 2 show the main KEEG pathways and UniProt keywords for proteins differentially identified in the sett roots of the first cutting of seed pieces obtained by STRING.

In the sett roots of the fifth cutting, only the proteins $40 \mathrm{~S}$ ribosomal protein S15, 40 S ribosomal protein S4, 40 S ribosomal protein $\mathrm{S} 16$, and $60 \mathrm{~S}$ ribosomal protein $\mathrm{L} 2$, which were differentially identified, interacted with one another, as may be observed in Figure 2B. The four interacting proteins were ribosomal proteins that were exclusively identified in the roots of the fifth cut (Table S2). Four 14-3-3 family proteins (14-3-3-like protein, 14-3-3-like protein GF14 chi, 143-3-like protein $16 \mathrm{R}$, and $14-3-3$-like protein $\mathrm{E})$ were also detected in the sett roots of the fifth cut. However, the PPI network failed to reveal any evidence of interaction between them (Figure 2B). Table 3 shows the INTERPRO protein domains and features of the five proteins from the PPI network for the proteins differentially identified in the sett roots of the fifth cutting.

\section{Discussion}

Morphological divergence was not observed in the sett roots of RB966928 for the first and fifth cuttings. However, proteome analysis showed a reduction in the number of proteins (25.6\% less proteins) in the sett roots of the fifth cutting, perhaps related to reduced crop productivity. Essential proteins for photosynthesis, photorespiration, glycolytic pathway, phytohormone biosynthesis, ribosomal subunits, transcription and elongation factors, protein and amino acid biosynthesis, defense against pathogens, in addition to different types of biotic and abiotic stress, identified in the sett roots of the first cut, were different or absent in the roots of the fifth cut.

Proteins related to biotic and abiotic stresses and defense against pathogens commonly described in other plant species were identified in the sett roots of the first and fifth cuts in sugarcane. The number of proteins related to biotic and abiotic stress identified in the sett roots of the first cut was more than three times greater than the number of proteins related to biotic and abiotic stress identified in the sett roots of the fifth cut. Furthermore, the number of proteins related to defense against pathogens identified in the sett roots of the first cut was four times greater than the number of proteins produced for defense against pathogens identified in the sett roots of the fifth cut. Proteins induced under thermal stress conditions were highlighted in the sett roots of the first cut.

Heat shock protein families are necessary to protect cells from heat and various damages by normalizing cellular function during recovery processes (Morimoto et al., 1994; Parsell and Lindquist, 1994; Nover et al., 1996). Seven principal HSP families have been described, based on their molecular masses: Hsp110, Hsp100, Hsp90, Hsp80, Hsp70, Hsp40s, and sHsp (small Hsp) (Gupta et al., 2010; Park and Seo, 2015; Verna et al., 2019). Nine HSP or HSP precursors (Hsp70-2, Hsp70-1, Hsp70-3, Hsp60, Hsp80, Hsp80-2, Hsp902, Hsp90-7, and chloroplast envelope membrane $70 \mathrm{kDa}$ heat shock-related protein) were detected in the sett roots of the first cut in RB966928. Several studies have indicated that HSPS play an essential role in the survival of plants under thermal stress (Luján et al., 2009; Hu et al., 2010; Li et al., 2014) and greater tolerance to water and salt stress (Augustine et al., 2015). 
The chloroplast envelope membrane $70 \mathrm{kDa}$ heat shockrelated protein was exclusively detected in the sett roots of the cultivar RB966928 of the first cut forms a complex of Hsp families that are induced under thermal stress conditions. The chaperonin CPN60-2 mitochondrial precursor (HSP60) was also detected exclusively in the sett roots of the first cut. Chaperonins prevent the misfolding of polypeptides and promote proper refolding and assembly of unfolded polypeptides generated under stress conditions in the mitochondrial matrix, which may be induced by a series of biotic and abiotic stresses, such as exposure to cold, ultraviolet light, water deficit, and tissue remodeling (Boston et al., 1996; Hartl et al., 2011). Under field conditions, sugarcane regrowth often occurs at elevated temperatures, causing the accumulation of folded and unfolded proteins. The higher amount of HSPs and sHSPs in the sett roots of the first cut may indicate a better response under high thermal stress conditions. Furthermore, the absence of the four HSP70, HSP60, HPS80, HSP 90-2, and HPS82 in the sett roots of the fifth cut, may reduce the ability of the axillary buds of plants of the fifth cut to detect and respond to thermal and other stresses (abiotic and biotic), and soil - plant interaction, mediated by the sett roots, may alter parameters that reduce the ability of regrowth of the axillary buds.

Eleven proteins related to biotic and abiotic stress (20 kDa chaperonin/chloroplast precursor, BiP4, BiP5, vacuolar ATP synthase catalytic subunit $A$, isoflavone reductase homolog, Ras-related protein Rab7A, seed lipoxygenase-2, glutathione reductase cytosolic, flavonol synthase, aminopeptidase/ chloroplast precursor, and 1-aminocyclopropane-1carboxylate oxidase) were identified in the sett roots of the first cut; however, they were absent in the sett roots of the fifth cut. The $20 \mathrm{kDa}$ chaperonin, a chloroplast precursor (CPN20), shows to function as a co-chaperone and CPN60 to promote proper refolding and assembly of unfolded polypeptides generated under stress. A review by Zhao and Liu (2018) highlighted the importance of the structure and function of the chaperonin-chloroplast system because chloroplasts have been suggested as sensors for various environmental stresses. Two BiP proteins (BiP4 and BiP5), detected in the sett roots of the sugarcane cultivar RB966928 of the first cut, are molecular chaperones of the endoplasmic reticulum that acts on protein folding and maturation (Carvalho et al., 2014). In the absence of BiP, many secretory pathway proteins do not assume their active conformation and precipitate in the endoplasmic reticulum (Pobre et al., 2019). Several studies have demonstrated the role of BiP proteins in plant protection under various stress conditions (Alvim et al., 2001; Wang et al., 2005; Costa et al., 2018; Valente et al., 2009; Reis et al., 2011).

The vacuolar ATP synthase catalytic subunit A (V-ATPases) proteins hydrolyze ATP to ADP and $\mathrm{Pi}$ coupled with $\mathrm{H}^{+}$ transport (Toei et al., 2010). The transcript levels of VATPases are regulated by environmental stresses such as salinity, heat, and drought responses that help plants maintain their water balance (Okamoto and Futai, 2018). The isoflavone reductase homolog (IFR; EC 1.3.1.-) catalyzes a stereospecific NADPH-dependent reduction to (3R)isoflavanone (Wang et al., 2006), and a greater expression of IFR has been shown after induction by UV, wounding, pathogen infection, and cold (Lucheta et al., 2007), indicating the role of IFR in responding to stressful situations. The Rasrelated protein Rab7A is localized mainly to late endosomes (Bucci et al., 2000; Vieira et al., 2003; Saito-Nakano et al., 2007). The $R a b 7$ gene expression in rice is differentially regulated by environmental stimuli, such as cold, $\mathrm{NaCl}$, dehydration, and abscisic acid (Nahm et al., 2003). Guerra and Bucci (2016) reported the main functions of the small GTPase Rab7, highlighting that the central role of Rab7 in correct cargo selection, biogenesis, positioning, motility, and functioning of lysosomes, phagolysosomes, and autolysosomes is fundamental for many cellular processes. The seed lipoxygenase-2 (LOX; EC 1.13.11.12) catalyzes the addition of molecular oxygen to polyunsaturated fatty acids to produce unsaturated fatty acid hydroperoxide. A review by Porta and Rocha-Sosa (2002) reported recent advances in the role of LOXs in the physiology of plants.

Glutathione reductase cytosolic (GR; EC 1.6.4.2) play an important role in protecting cells against oxidative damage (Trivedi et al., 2013). GR overexpression studies in various plants have revealed that it protects the cell from abiotic stress induced by oxidative damage. Flavonol synthase (FLS; EC 1.14.11.-) catalyzes the early step in the flavonoid biosynthesis pathway, leading to the production of flavanols and anthocyanins against oxidative damage (Jin et al., 2005). The 1-aminocyclopropane-1-carboxylate oxidase (ACO; EC 1.14.17.4), detected only in the sett roots of the first cut, is related to biosynthesis of the ethylene phytohormone and in the plant's defense against biotic and abiotic stresses (Van de Poel et al., 2015). The absence of ACO in the sett roots of the fifth cut suggests a loss of capacity by roots to respond to biotic and abiotic stresses, which may restrict the budding process of axillary buds at advanced cutting ages.

The protein cell division cycle protein 48 homolog, ubiquitinactivating enzyme $\mathrm{E} 1$, proteasome subunit beta type 1 , glucan endo-1,3-beta-glucosidase GII precursor, and trypsin inhibitor $B$, exclusively identified in the sett roots of the first cut, are reported to be essential against pathogens. The cell division cycle protein 48 homolog and ubiquitin-activating enzyme E1 in the sett roots of the first cut, although missing in the sett roots of the fifth cut, suggest that defensive responses to pathogens in the fifth cut may be deficient, causing plants to be more exposed to attacks by pathogenic microorganisms. The cell division cycle protein 48 homolog (product of $C d c 48$ gene) is an essential protein for plant cell cycle progression, and it is a component of protein quality control in plant immunity against pathogen infections (Chisholm et al., 2006; Jones and Dangl, 2006; Dangl et al., 2013; Bègue et al., 2018). The proteasome subunit beta type 1 (EC 3.4.25.1) is a core component of the $20 \mathrm{~S}$ proteasome involved in several aspects of plant immunity (Üstün et al., 2016).

The Glucan endo-1,3- $\beta$-glucosidase GII precursor degrades fungal cell walls; therefore, it may inhibit pathogen growth by directly acting as an elicitor of defense reactions (Shetty et al., 2009). The application of purified $\beta$-1,3-glucan, isolated from the cell walls of the pathogen, has been shown to protect a susceptible wheat cultivar from disease development, accompanied by accumulation of pathogenesis-related proteins and callose. Trypsin inhibitor B is important in homeostasis, and changes in protease function leading to pathogenesis. It also maintains physiological homeostasis and helps the plant's innate defense machinery (Arnaiz et al., 2018).

Among the higher number of proteins related to biotic and abiotic stresses and defense against pathogens in the sett roots of the first cut, only one protein of defense against pathogens ( $\alpha$-amylase inhibitors), and six proteins related to biotic and abiotic stresses different from those detected in sett roots of the first cut (spermidine synthases, $26 \mathrm{~S}$ protease regulatory subunit $6 \mathrm{~A}$ homolog, nitrilase 4 , glycine-rich RNA- 
binding proteins, profilin 6 , and $\alpha$-amylase inhibitor) were identified in the sett roots of the fifth cut from RB966928. Proteins related to biotic and abiotic stresses and defense against pathogens originally synthesized in the sett roots of the first cut were absent at the fifth cut. In contrast, other biotic and abiotic stresses were evident at advanced cutting ages.

Spermidine synthases (SPDS; EC 2.5.1.16) are involved in normal cellular metabolism and stress response signaling regulators in stress-signaling pathways, leading to stress tolerance mechanisms in Arabidopsis thaliana plants under stress conditions (Kasukabe et al., 2004; Sekula and Dauter, 2019). Polyamines have been implicated in a wide range of biological processes in plant growth and development, including senescence, environmental stress, and infection by fungi and viruses (Kaur-Sawhney et al., 2003; Pál et al., 2018). The $26 \mathrm{~S}$ protease regulatory subunit $6 \mathrm{~A}$ homolog is involved in the ATP-dependent degradation of ubiquitinated proteins in the protein catabolic process (Marino et al., 2012; Dudler, 2013). The 265 protease regulatory subunit $6 A$ in the roots of the fifth cut may be another indication for response to stress situations due to infection by pathogens detected at this cutoff age, where defective or exogenous proteins from pathogens must be degraded by proteosomes.

Nitrilase 4 (NIT; EC 3.5.5.1) is an isozyme of the nitrilase superfamily that catalyzes the hydrolysis of nitrile compounds to carboxylic acids and ammonia. Nitrilases are tissue-specific (reviewed by O'Reilly and Turner, 2003; Howden and Preston, 2009). NIT4 activity (detected in the sett roots of the fifth cut in this study) is described as higher in senescent leaves of $A$. thaliana than in non-senescent ones (Piotrowski et al., 2001). The authors suggested that the upregulation of NIT4 activity during senescence may be linked to increased ethylene biosynthesis and cyanide production.

$\alpha$-Amylase inhibitors ( $\alpha$-Als) are part of the natural defense mechanisms against pests by interfering with their digestion process. They may also provide access to new pest management strategies (Kaur et al., 2014). Several important roles of glycine-rich RNA-binding proteins (GR-RBPs) in response to abiotic stresses in actively proliferating organs, such as young plants, root tips, and flowers, were reviewed by Wang et al. (2018). Profilin 6 represents a group of proteins (profilins) that are key regulators of actin cytoskeleton dynamics through their interaction with monomeric actin (Gactin). Interaction of profilins with phosphatidyl inositol-4,5bisphosphate, a major component of cell-signaling transduction pathways, is essential for integrating stress responses through cytoskeleton rearrangement, in addition to processes such as cell movement and cytokinesis driven by actin polymerization dynamics (Wilke and Otto, 2003).

Quantitative differences were observed in the expression of genes involved in the synthesis of stress proteins identified in the sett roots of the first and fifth cuts of RB966928. However, the most striking difference in the proteome of the sett root in the first and fifth cuts was related to the essential proteins for photosynthesis, photorespiration, glycolytic pathway, control of gene expression, and protein and amino acid biosynthesis to plant growth and development exclusively observed in the sett roots of the first cut. The triosephosphate isomerase, ribulose 1,5-bisphosphate carboxylase/oxygenase (RuBisCO) subunit binding protein $\alpha$-subunit, RuBisCO subunit binding protein $\beta$-subunit and transketolase 10 are essential proteins for photosynthetic processes detected in the sett roots of the first cut although absent in the sett roots of the fifth cut. Triosephosphate isomerase (TPI; EC 5.3.1.1) is present in several metabolic pathways involved in glycolysis, gluconeogenesis, and the Calvin cycle. Chen and Thelen (2010) showed that a reduction in gene expression and plastid TPI activity (pdTPI) resulted in a stunted plant that failed to reach reproductive maturity. The RuBisCO (EC 4.1.1.39) subunit binding protein $\alpha$-subunit and $\beta$-subunit are recognized as chaperonin 60 , which is intimately involved in the assembly of the RuBisCo enzyme (Zhao and Liu, 2018). Transketolase (TKT; EC 2.2.1.1) is integral to the Calvin cycle and the oxidative pentose phosphate pathway of higher-plant chloroplasts (Khozaei et al., 2015).

The aminomethyltransferase mitochondrial precursor, glycine dehydrogenase mitochondrial, serine hydroxymethyltransferase mitochondrial, malate synthase glyoxysomal, and aconitate hydratase cytoplasmic are essential proteins for photorespiration processes detected in the sett roots of the first cut; however, they are absent in the sett roots of the fifth cut. The aminomethyltransferase mitochondrial precursor (AMT; EC 2.1.2.10) protein is one of the four enzymes that work in the glycine cleavage system, producing methyl groups transferred to other key molecules, such as purines and methionine. The glycine cleavage system is required for photorespiration in $C_{3}$ plants (Timm et al., 2015). Glycine dehydrogenase $B$, mitochondrial (GDC; EC 1.4.4.2), is also an integral part of the photorespiratory system involved in the glycine catabolic process (Palmieri et al., 2010). Serine hydroxymethyltransferase mitochondrial (SHMT; EC 2.1.2.1) functions in the photorespiratory pathway by catalyzing serine and glycine interconversion. Glycine and serine are intermediates in the photorespiration of glycerate to 3-phosphoglycerate. Moreno et al. (2005) observed that, in addition to acting as an essential protein for photorespiration, SHMT is involved in controlling cell damage caused by abiotic stress, such as high light, salt rates, and also in the defense response of plants. The malate synthase glyoxysomal (MS; EC 2.3.3.9) enzyme is specific to the glyoxylate cycle responsible for malate synthesis from acetylCoA and glyoxylate in the glyoxysome. In addition to gluconeogenesis, the glyoxylate cycle is also important for replenishing succinate in the TCA cycle, the major cellular machinery for oxidative metabolism and energy production (Pua et al., 2003). The cytoplasmic aconitate hydratase (cACO; EC 4.2.1.3) is involved in the reversible conversion of citrate to isocitrate, crucial to the Krebs cycle, which plays a key role in aerobic respiration. Carrari et al. (2003) have shown that a reduction in aconitase activity causes a stunted phenotype in the early stages of tomato (Lycopersicon pennellii) development plants.

Phosphoglucomutase and fructokinases are essential proteins in the glycolytic pathway detected in the sett roots of the first cut and absent in the sett roots of the fifth cut. Essential proteins for glycolytic via and respiration, such as the phosphoglucomutase (cPGM; EC 5.4.2.2) isozymes identified in the sett roots of the first cut and absent in the roots of the fifth cut, catalyze the reversible interconversion of glucose 6-phosphate and glucose 1-phosphate. The absence of CPGM in the sett roots of the fifth cut may be related to metabolic changes in the radicular cells and probable deficit in the conduction of water and nutrients to the axillary bud, which results in a lower sprouting rate, less 
Table 1. KEEG Pathways for proteins differently identified in the sett roots of the first cutting of sugarcane seed-pieces obtained by STRING 11.0 database.

\begin{tabular}{|l|l|l|l|}
\hline $\begin{array}{l}\text { KEEG Pathways } \\
\text { Pathways }\end{array}$ & Description & $\begin{array}{l}\text { Count in gene } \\
\text { set }\end{array}$ & $\begin{array}{l}\text { False discovery } \\
\text { rate }\end{array}$ \\
\hline cmo01110 & Biosynthesis of secundary metabolites & 15 of 958 & $1.05 \mathrm{e}-08$ \\
\hline cmo01200 & Carbon metabolism & 9 of 229 & $1.79 \mathrm{e}-08$ \\
\hline cmo01100 & Metabolic pathways & 18 of 1685 & $1.79 \mathrm{e}-08$ \\
\hline cmo01230 & Biosynthesis of amino acids & 8 of 201 & $7.84 \mathrm{e}-08$ \\
\hline cmo00630 & Glyoxylate and dicarboxylate metabolism & 6 of 69 & $7.84 \mathrm{e}-08$ \\
\hline cmo04141 & Protein processing in endoplasmic reticulum & 6 of 168 & $8.61 \mathrm{e}-06$ \\
\hline cmo00710 & Carbon fixation in photosynthetic organisms & 4 of 64 & $6.23 \mathrm{e}-05$ \\
\hline cmo00260 & Glycine, serine and threonine metabolism & 4 of 72 & $8.49 \mathrm{e}-05$ \\
\hline cmo01210 & 2-Oxocarboxylic acid metabolism & 3 of 44 & 0.00054 \\
\hline cmo00670 & One carbon pool by folate & 2 of 18 & 0.0031 \\
\hline cmo00010 & Glycolysis / Gluconeogenesis & 3 of 111 & 0.0059 \\
\hline cmo00500 & Starch and sucrose metabolism & 3 of 116 & 0.0061 \\
\hline cmo04144 & Endocytosis & 3 of 145 & 0.0105 \\
\hline cmo00020 & Citrate cycle (TCA cycle) & 2 of 44 & 0.0116 \\
\hline cmo00030 & Pentose phosphate pathway & 2 of 47 & 0.0122 \\
\hline cmo00051 & Fructose and mannose metabolism & 2 of 51 & 0.0134 \\
\hline cmo00270 & Cysteine and methionine metabolism & 2 of 84 & 0.0320 \\
\hline cmo03018 & RNA degradation & 2 of 94 & 0.0372 \\
\hline
\end{tabular}

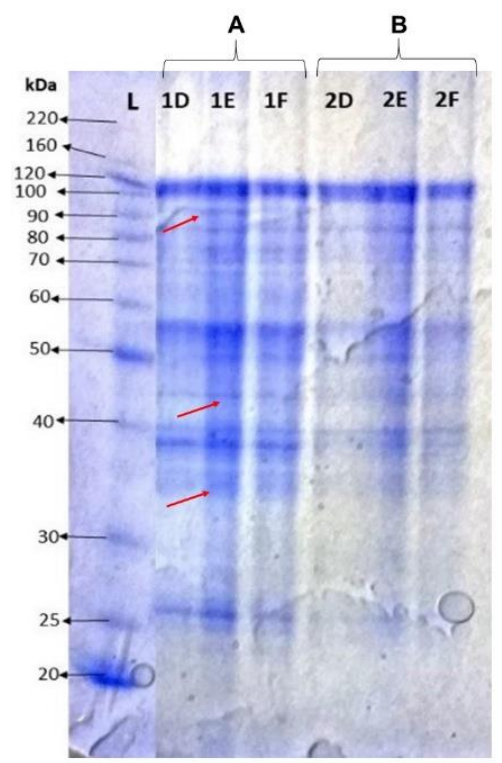

Figure 1. 1D SDS-PAGE with the protein profile from sett roots of the sugarcane cultivar RB966928. A - Roots of first cut; B - Roots of fifth cut; $\mathbf{L}$ - Ladder. Red arrows indicate differential bands for the cut ages.

Table 2. UniProt Keywords for proteins differently identified in the sett roots of the first cutting of sugarcane seed-pieces obtained by STRING 11.0 database.

\begin{tabular}{|l|l|l|l|}
\hline $\begin{array}{l}\text { UniProt Keywords } \\
\text { Keyword }\end{array}$ & Description & $\begin{array}{l}\text { Count in gene } \\
\text { set }\end{array}$ & $\begin{array}{l}\text { False discovery } \\
\text { rate }\end{array}$ \\
\hline KW-0346 & Stress response & 5 of 52 & $6.39 \mathrm{e}-06$ \\
\hline KW-0809 & Transit peptide & 3 of 26 & 0.00086 \\
\hline KW-0554 & One-carbon metabolism & 2 of 14 & 0.0092 \\
\hline KW-0496 & Mitochondrion & 3 of 70 & 0.0092 \\
\hline KW-0489 & Methyltransferase & 4 of 254 & 0.0189 \\
\hline KW-0067 & ATP-binding & 7 of 851 & 0.0189 \\
\hline KW-0032 & Aminotransferase & 2 of 38 & 0.0255 \\
\hline KW-0460 & Magnesium & 3 of 161 & 0.0314 \\
\hline KW-0663 & Pyridoxal phosphate & 2 of 55 & 0.0381 \\
\hline KW-0560 & Oxidoreductase & 5 of 607 & 0.0433 \\
\hline
\end{tabular}


A

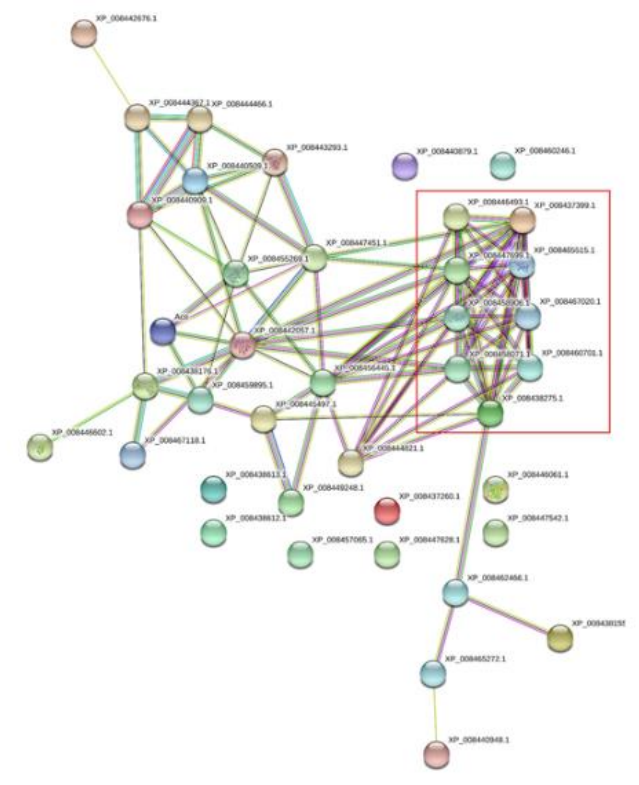

B

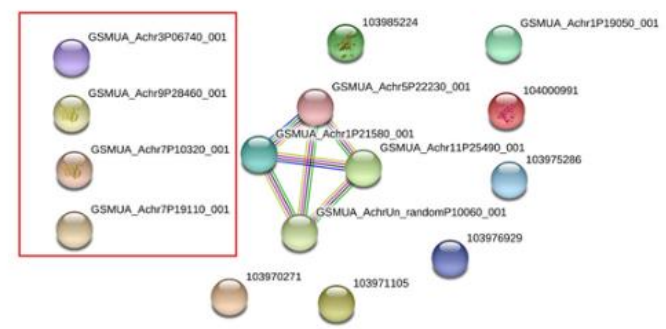

Figure 2. Protein-protein analysis by STRING 11.0. (A) STRING PPI network of some differential proteins identified in sett roots of first cut sugarcane. Network contains 95 edges (vs. 34 expected edges); enrichment $p$-value < 1.0e-16. (B) STRING PPI network of some differential proteins identified in sett roots of fifth cut sugarcane. PPI network contains 15 nodes with 6 edges (vs. 4 expected edges); enrichment $p$-value $<0.199$. Minimum required interaction score was set at 0.400 (medium confidence) for both analyses.

Table 3. INTERPRO Protein Domains and Features for proteins identified in the sett roots of sugarcane obtained by STRING 11.0 database.

\begin{tabular}{|l|l|l|l|}
\hline INTERPRO Protein Domains and Features & & \\
\hline Domain & Description & Count in gene set & False discovery rate \\
\hline IPR036815 & $14-3-3$ domain superfamily & 4 of 25 & $2.42 \mathrm{e}-08$ \\
\hline IPR023410 & $14-3-3$ domain & 4 of 25 & $2.42 \mathrm{e}-08$ \\
\hline IPR000308 & $14-3-3$ protein & 4 of 25 & $2.42 \mathrm{e}-08$ \\
\hline IPR023409 & $14-3-3$ protein, conserved site & 3 of 22 & $1.77 \mathrm{e}-06$ \\
\hline IPR014722 & Ribosomal protein L2, domain 2 & 2 of 36 & 0.0012 \\
\hline
\end{tabular}

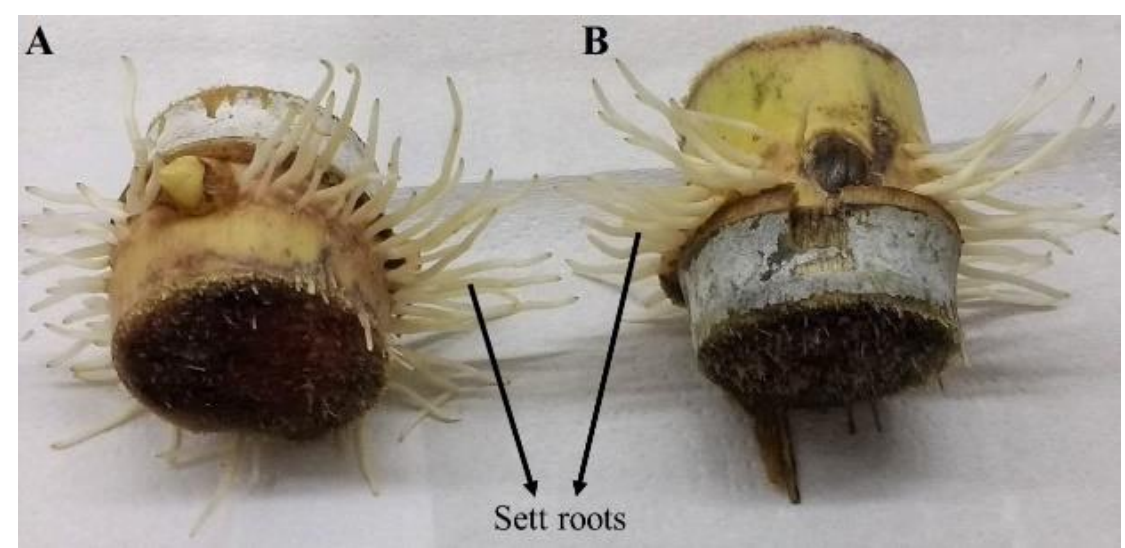

Figure 3. Seed-pieces with individualized axillary buds and sett roots developed from the node's root primordia. A - Seed-piece of first cut; B - Seed-piece of fifth cut. 
robust plants, and decreased agricultural productivity of the sugarcane plantation (Malinova et al., 2014). Fructokinases (FRKs; EC 2.7.1.4) are important enzymes that catalyze the key metabolic step of fructose phosphorylation (Riggs et al., 2017) to enter metabolism and plant development (review by Stein and Granot, 2018).

S-adenosylmethionine synthetase 1 (SAM; EC 2.5.1.6) is an essential protein that controls gene expression detected in the sett roots of the first cut and absent in the sett roots of the fifth cut. Gong et al. (2014) showed that overexpression of the SAM gene in tomato (Lycopersicon esculentum) provided a stronger root system, exhibited a significant increase in tolerance to alkali stress and maintained nutrient balance, higher photosynthetic capacity, and lower oxidative stress.

Proteins involved in ribosomal subunit formation (60S ribosomal protein $\mathrm{L} 12$ and $60 \mathrm{~S}$ ribosomal protein L7), elongation factors (elongation factor 2) for protein biosynthesis, and proteins involved in amino acid biosynthesis (5-methyltetrahydropteroyltriglutamate-homocystein

methyltransferase, ketol-acid reductoisomerase chloroplast precursor, aspartate aminotransferase cytoplasmic isozyme 1 , and alanine aminotransferase 2) were exclusively identified in the sett roots of the first cut. Elongation factor 2 (eEF-2) is originally a GTP-binding protein involved in the translation process for polypeptide chains and protein synthesis, and eEF-2 is also associated with plant cold (Guo et al., 2002; Shi et al., 2019).

The enzyme 5-methyltetrahydropteroyltriglutamatehomocystein methyltransferase (MET6; EC 2.1.1.14) catalyzes the reaction of the last step in L-methionine biosynthesis (Eichel et al., 1995). The reaction catalyzed by by Ketol-acid reductoisomerase (KARI; EC 1.1.1.86) consists of the biosynthesis of branched-chain amino acids (Lee et al., 2005). Aspartate aminotransferase cytoplasmic isozyme 1 (AAT2; EC 2.6.1.1) catalyzes the reversible reaction of transamination between aspartate and 2-oxoglutarate to generate glutamate and oxaloacetate, regulating the synthesis of aspartate or catabolism. Alanine aminotransferase 2 (AlaAT; EC 2.6.1.2) catalyzes the reversible conversion of pyruvate and glutamate into alanine and $\alpha$-oxoglutarate. Studies have shown that AlaAT transcript levels could be induced by hypoxic conditions (Ricoult et al.,

2006; Miyashita et al., 2007) and also by light and N (Xu et al., 2017), regulating shoot root allocation.

Although different proteins involved in phytohormone biosynthesis, such as phospholipase D1 precursor, 1aminocyclopropane-1-carboxylate oxidase, and pyruvate dehydrogenase E1 component $\beta$-subunit, were identified in sett roots of the first cut, only the 14-3-3-like protein family was detected in the sett roots of the fifth cut. The Phospholipase D 1 precursor (PLD 1; EC 3.1.4.4), exclusively detected in the sett roots of the first cut, cleaves the phosphodiester bond in the phospholipid, yielding phosphatidic acid (PA) and a free head group (Wang, 2000; Chen et al., 2011). Phospholipases may also bind and modulate other membrane regulatory proteins, including the subunits of G-protein complexes and sphingosine kinase (Pandey, 2016). Therefore, the maintenance of homeostasis and membrane stability is partly ensured by phospholipases (Lanteri et al., 2008; Takác et al., 2019). According to Takác et al. (2019), the various mechanisms of action of phospholipases have suggested that these enzymes are involved in plant responses to drought, cold, heat, salt, osmotic pressure, heavy metal stress, phosphorus deficiency, and pathogens. The absence of PLD 1 in the sett roots of the fifth cut may imply changes in the various mechanisms of action described for phospholipases and, consequently, reduced growth and development of axillary buds.

The 1-aminocyclopropane-1-carboxylate oxidase (ACO; EC 1.14.17.4) is related to the biosynthesis of ethylene phytohormones. It is an important regulator of many developmental and physiological processes, such as seed dormancy, germination, vegetative growth, flowering, climacteric fruit ripening, and senescence (Houben and Van de Poel, 2019). The pyruvate dehydrogenase E1 component $\beta$-subunit (PDH E1- $\beta$; EC 1.2.4.1) is important for regulating the distribution of PIN proteins in the cytoplasmic membrane of cells. PIN proteins are integral membrane proteins involved in transporting across membranes (Guan et al., 2019; Ohbayashi et al., 2019). Low expression of the gene for PDH E1 $\beta$ inhibited the transport of auxin, which is crucial for developing roots, and other organs mediated by auxin. Subsequently, the non-detection of PDG E1 $\beta$ in the roots of the fifth cut may be related to defective transport of auxins, with a consequent reduction in enzymatic activities, respiration, and amino acid metabolism of the sett roots.

The $14-3-3$-like protein family represents $25 \%$ of the proteins exclusively detected in the sett roots of the fifth cutting from RB966928 (14-3-3-like protein, 14-3-3-like protein GF14 chi, 14-3-3-like protein 16R, and 14-3-3-like protein E). Camoni et al. (2018) highlighted the role of 14-3-3 proteins in regulating hormonal signaling, biosynthesis, and transport. The 14-3-3like proteins were also detected exclusively in the axillary buds of the fifth cut of sugarcane cultivar RB867515 (Maranho et al., 2019). It has been reported that 14-3-3-like proteins in $A$. thaliana may function as positive regulators of the phytohormone brassinosteroids, while 14-3-3 isoforms have different regulatory properties for brassinosteroid signaling (Lee et al., 2020). In contrast, in $A$. thaliana transgenic plants overexpressing the TA14-3-3 gene (from Triticum aestivum), 14-3-3-like proteins are growth inhibitors that provide plants with delayed growth rates, shorter primary roots, and delayed flowering (Jing et al., 2013). The 14-3-3-like proteins were exclusively found in the sett roots of the fifth cut from RB966928 may indicate an incidence of stress that activates genes for 14-3-3-like proteins that act on signaling routes in the sett root cells. The large expression of genes for this group of proteins may inhibit the complete development of the sett roots of the fifth-cut specimens. The 14-3-3-like proteins, exclusively in the sett roots of the fifth cut, and the absence or reduction of other proteins not detected at this cut-off age may cause deficient soil-plant communication, interfering with the sprouting of axillary buds.

Ribosomal proteins (40S and 60S) represent another $25 \%$ of the proteins exclusively detected in the sett roots of the fifth cutting from RB966928. The 405 and 605 ribosomal proteins are essential for the organization of the ribosomal small subunit assembly and ribosomal larger subunit assembly, respectively, during ribosome biogenesis (Carroll, 2013; SáezVásquez and Delseny, 2019). Several studies have shown that plant-pathogen interactions in the early stages cause transcriptional reprogramming, coupled to translational regulation. In current study, the authors suspect that the expressive proportion of ribosomal proteins in the sett roots of the fifth cut from RB966928 may be related to plant responses to biotic stress.

Differences in the proteome of the sett roots from RB966928 in the first and fifth cuts detected in current study supports 
the hypothesis that the proteome of sett roots may change after successive cuts in sugarcane culture. A reduction in the number of proteins (25.6\%) was observed in the roots of the fifth cut; however, $34 \%$ of the proteins identified exclusively in the first cut were absent in the fifth cut. Proteome analysis of sett roots in the first and fifth cuts showed that the changes after successive cuts were mainly qualitative. Essential proteins for the promotion of plant growth and development involved with photosynthesis, photorespiration, glycolytic pathway, control of gene expression, and protein and amino acid biosynthesis were not detected in the roots of the fifth cut. In addition, while stress proteins exclusive to the first cut roots are involved in protecting and guaranteeing the plant development processes, stress proteins exclusively identified in the fifth cut may act as growth inhibitors, providing plants with delayed growth. The absence of essential proteins to promote plant growth and development and stress proteins involved in protecting and guaranteeing the development processes in sett roots of the fifth cut from RB966928 may reduce budding of the axillary buds. The reduction in agricultural productivity of RB966928 in the fifth cut was approximately $51 \%$ (information by farmers). The reduction in the budding of axillary buds may generate less vigorous plants for the next sugarcane productive cycle and compromise the longevity of cane fields. The development of strategies to induce the synthesis of proteins involved in photosynthesis, photorespiration, glycolysis, control of gene expression, protein biosynthesis, and amino acids (undetected in the roots of the fifth cut) may be an alternative to increase the longevity of the cane fields of the cultivar RB962869. The detailed list of proteins identified in the first cut but absent in the fifth cut reported in the present study is relevant because it opens a perspective for further researches that employ biotic or abiotic elicitors to induce gene expression. Application of biotic or abiotic elicitors may be a promising strategy to induce gene expression of the essential proteins absent in the sett roots of the fifth cut, increasing the agricultural productivity and longevity of cane fields.

\section{Materials and methods}

\section{Plant material - sett roots of cultivar RB966828}

Sugarcane stalks of the 10-month-old cultivar RB966928 in the first and fifth cuts were collected from farms of Nova Aralco Industrial $\left(20^{\circ} 53^{\prime} 29.82^{\prime \prime} \mathrm{S}, 50^{\circ} 26^{\prime} 55.25^{\prime \prime} \mathrm{W}\right)$ in the state of São Paulo, Brazil. The sugarcane plants were cultivated in dystrophic Argisol-type soil with low water availability and medium cation exchange capacity. Based on leaf count by the Kuijper system, described by Van Dillewijn (1952), only axillary buds from the fourth to the ninth nodes were used to avoid the greater influence of auxins in the axillary buds near the stem apex. Axillary buds from plant cane (first cut) and plants of the fifth cut (fourth ratoon) were individualized and planted in vermiculite to initiate sprouting and sett root development, in labeled 10-L trays, with a spacing of $3 \mathrm{~cm}$ between samples. They were irrigated every two days.

Sprouting occurred in a greenhouse at $22^{\circ} \mathrm{C}$ after 5 days. The sett roots of each cutting age (first and fifth; Figure 3 ) were excised with a scalpel, instantly frozen in liquid nitrogen, and stored in an ultra-freezer at $-80^{\circ} \mathrm{C}$ until use. At each cutting age (first and fifth cut), the sett roots were taken from three plants (three plants from the first cut and three plants from the fifth cut; biological triplicate) and divided into three aliquots (technical triplicates).

\section{Extraction, quantification, and protein digestion}

Sett roots $(200 \mathrm{mg}$ ) extracted from the first and fifth cutting stages were used in triplicate from each biological replicate. Total proteins were extracted using the modified TCAacetone method for sugarcane axillary buds (Maranho et al., 2018). Proteins were quantified by fluorimetry (Qubit Fluorometer 1.0; Invitrogen, Carlsbad, CA, USA) with a Qubit Protein Assay Kit (Invitrogen, Carlsbad, CA, USA). The complex mixture of proteins was pre-fractionated by 1D SDS-PAGE (sodium dodecyl sulfate polyacrylamide gel electrophoresis), with $12 \%$ and $5 \%$ visualization and stacking gel, respectively. Electrophoresis lasted $\sim 3 \mathrm{~h}$ at $200 \mathrm{~V}$. Gel was then stained with $0.1 \%$ Coomassie Brilliant Blue R-250. The SDS-PAGE verified previously differences (Figure 1 , red arrows) in protein expression in each sample and assessed protein extraction quality.

Tryptic digestion was performed following the method described by Villén and Gygi (2008). Disulfide bonds were reduced by incubation in dithiothreitol (DTT) solution (DTT 5 $\mathrm{mM}$ in $50 \mathrm{mM} \mathrm{NH}_{4} \mathrm{HCO}_{3}$ - ammonium bicarbonate). Cysteine residues were alkylated by incubation in an alkylation solution (14 $\mathrm{mM}$ iodoacetamide and $50 \mathrm{mM} \mathrm{NH}_{4} \mathrm{HCO}_{3}$ ). Proteins were digested with Trypsin/Lys-C Mix (Promega, Madison WI, USA) at a final concentration of $20 \mathrm{ng} \mu \mathrm{L}^{-1}$ for $16 \mathrm{~h}$ at $37^{\circ} \mathrm{C}$.

\section{UPLC separation, MS analysis, and Bioinformatics}

The protein digest was analyzed with an ultra-high performance liquid chromatograph ACQUITY UPLC M-Class System (Waters ${ }^{\text {TM }}$, Milford MA USA), coupled to a time-offlight high-resolution mass spectrometer (Xevo G2-XS Tof, Waters $^{\text {TM }}$ ) equipped with an electrospray ionization source. Chromatographic separation was performed using an Acquity UPLC $^{\circledR}$ M-Class HSS T3 column packed with $1.8 \mu \mathrm{m}$ particle size, $300 \mu \mathrm{m} \times 150 \mathrm{~mm}$ column (Waters $\mathrm{s}^{\mathrm{m}}, \mathrm{UK}$ ), at a flow rate of $6 \mu \mathrm{L} \mathrm{min}{ }^{-1}$. The gradient mixture of solvents $A\left(\mathrm{H}_{2} \mathrm{O}\right.$ with $0.1 \%$ formic acid; v:v) and $B$ (acetonitrile with $0.1 \%$ formic acid, v/v) was as follows: $3 \%$ B 0-1 min, 40\% B 1-80 min, 97\% B 80-90 min, maintained at 97\% B 90-97 min, 3\% B 97-100 min, and maintained at $3 \%$ B $100-103 \mathrm{~min}$ at $40^{\circ} \mathrm{C}$. Capillary voltage was operated in positive mode, set at a 3.0 capillary, sampling cone $40 \mathrm{~V}$, and desolvation gas $600 \mathrm{~L} \mathrm{~h}-1 / 400^{\circ} \mathrm{C}$. Data were collected from $\mathrm{m} / \mathrm{z} 50$ to 2000 using MSe acquisition, scan time $=0.5$, and ramp collision energy $15-45$ V.

After LC-MS/MS, raw data files were processed and analyzed with ProteinLynx Global ServerTM 3.0.3, and the sequences were searched against the Viridiplantae and Saccharum taxonomy in the UniProtKB database (downloaded in April 2019). The following parameters were used for database searches: cleavage specificity, trypsin with one missed cleavage allowed, Min Fragment Ion Matches per Peptide $=2$, Min Fragment Ion Matches per Protein $=5$, Min Peptide Matches Per Protein $=1$, Fixed Modifier Reagent: Carbamidomethyl C; Variable Modifier Reagents: Oxidation M; FDR: $5 \%$.

KEEG Pathways, Uniprot Keywords, and INTERPRO protein domains and features enrichment analysis were performed using the multiple protein search interface of the STRING database (version 11.0) (Szklarczyk et al., 2019) to evaluate known and predicted protein relationships. Differential proteins in the sett roots of the sugarcane plant and of the fourth ratoon were compared against Cucumis melo and Musa acuminata protein databases, respectively, for protein- 
protein interaction network (PPI) analysis. Cucumis melo and Musa acuminata databases were selected due to more annotations of their biological processes and molecular functions in the STRING Consortium database and the lack of a Saccharum protein database.

All MS data were available via the jPOST Repository Database and ProteomeXchange with identifiers JPST001038 and PXD023098, respectively.

\section{Conclusion}

The absence of essential proteins to promote plant growth and development (proteins involved in photosynthesis, photorespiration, glycolytic pathway, control of gene expression, protein and amino acid biosynthesis), and stress proteins involved in protecting and guaranteeing the development processes in sett roots of the fifth cut may reduce the budding of the axillary buds. The reduction in the budding of axillary buds may generate less vigorous plants for the next sugarcane productive cycle and compromise the longevity of cane fields. The absence of essential proteins in sett roots compromises the main function of these roots to provide water and nutrients to the young developing shoots.

\section{Supplementary Material for Publication}

Link MS data deposited in jPOST repository. https://repository.jpostdb.org/ Acession: JPST001038. Link MS data deposited in ProteomeXchange. http://www.proteomexchange.org/ Acession: PXD023098.

\section{Conflict of Interest}

The authors declare no conflict of interest.

\section{Acknowledgments}

The authors would like to thank Nova Aralco Industry for the supply of biological material, the Coordination for the Upgrading of Higher Education Personnel (Coordenação de Aperfeiçoamento de Pessoal de Nível Superior (CAPES) [Finance Code 001], CAPES (AUXPE-PROEX-1799/2015CAPES-Process N. 23038.004610/2015-45) and Mass Spectrometry Laboratory of the Centro Complexo de Centrais de Apoio à Pesquisa (COMCAP/UEM) for technical support and proteomic analyses.

\section{References}

Alvim FC, Carolino SMB, Cascardo JCM, Nunes CC, Martinez CA, Otoni WC (2001) Enhanced accumulation of BiP in transgenic plants confers tolerance to water stress. Plant Physiol. 126: 1042-1054.

Arnaiz A, Talavera-Mateo L, Gonzalez-Melendi P, Martinez M, Diaz I, Santamaria ME (2018) Arabidopsis kunitz trypsin inhibitors in defense against spider mites. Front Plant Sci. 9: Article 986.

Augustine SM, Narayan JA, Syamaladevi DP, Appunu C, Chakravarthi M, Ravichandran V, Subramonian N (2015) Erianthus arundinaceus HSP70 (EaHSP70) overexpression increases drought and salinity tolerance in sugarcane (Saccharum spp. hybrid). Plant Sci. 232: 23-34.

Bègue $H$, Mounier A, Rosnoblet $C$, Wendehenne $D$ (2018) Toward the understanding of the role of $C D C 48$, a major component of the protein quality control, in plant immunity. Plant Sci. 279: 34-44.

Benez MM, Maranho RC, Maranho GB, Neiverth A, Santos MF, Carvalho ALO, Gonela A, Mangolin CA, Machado MFPS (2019) Proteome of germinating and dormant axillary buds of sugarcane and analysis of sprouting-related proteins. Plant Omics. 12: 15-24.

Boston RS, Viitanen PV, Vierling E (1996) Molecular chaperones and protein folding in plants. Plant Mol Biol. 32: 191-222.

Bucci C, Thomsen P, Nicoziani P, McCarthy J, van Deurs B (2000) Rab7: A key to lysosome biogenesis. Mol Biol Cell. 11: 467-480.

Camoni L, Visconti S, Aducci P, Marra M (2018) 4-3-3 Proteins in plant hormone signaling: doing several things at once. Front Plant Sci. 9: Article 297.

Carrari F, Nunes-Nesi A, Gibon Y, Lytovchenko A, Loureiro ME, Fernie AR (2003) Reduced expression of aconitase results in an enhanced rate of photosynthesis and marked shifts in carbon partitioning in illuminated leaves of wild species tomato. Plant Physiol. 133: 1322-1335.

Carroll AJ (2013) The Arabidopsis cytosolic ribosomal proteome: from form to function. Front Plant Sci. 4: Article 32.

Carvalho HH, Silva PA, Mendes GC, Brustolini OJ, Pimenta MR, Gouveia BC, Valente MA, Ramos HJ, Soares-Ramos JR, Fontes EP (2014) The endoplasmic reticulum binding protein BiP displays dual function in modulating cell death events. Plant Physiol. 164: 654-670.

Chen G, Snyder CL, Greer MS, Weselake RJ (2011) Biology and biochemistry of plant phospholipases. Crit Rev Plant Sci. 30: 239-258.

Chen M, Thelen JJ (2010) The plastid isoform of triose phosphate isomerase is required for the post germinative transition from heterotrophic to autotrophic growth in Arabidopsis. Plant Cell. 22: 77-90.

Chisholm ST, Coaker G, Day B, Staskawicz BJ (2006) Hostmicrobe interactions: shaping the evolution of the plant immune response. Cell. 124: 803-814.

Costa MD, Reis PA, Valente MA, Irsigler AS, Carvalho CM, Loureiro ME, Aragão FJ, Boston RS, Fietto LG (2008) A new branch of endoplasmic reticulum stress signaling and the osmotic signal converge on plant-specific asparagines-rich proteins to promote cell death. J Biol Chem. 283: 2020920219.

Dangl JL, Horvath DM, Staskawicz BJ (2013) Pivoting the plant immune system from dissection to deployment. Science. 341: 746-751.

Dudler R (2013) Manipulation of host proteasomes as a virulence mechanism of plant pathogens. Annu Rev Phytopathol. 51: 521-542.

Eichel J, Gonzalez JC, Hotze M, Matthews RG, Schroder J (1995) Vitamin-B12-independent methionine synthase from a higher plant (Catharanthus roseus). Molecular characterization, regulation, heterologous expression, and enzyme properties. Eur J Biochem. 230: 1053-1058.

Glover J (1967) The simultaneous growth of sugarcane roots and tops in relation to soil and climate. P S Afr Sug. 41: 143159.

Gong B, Li X, Vanden Langenberg KM, Wen D, Sun S, Wei M, Li Y, Yang F, Shi Q, Wang X (2014) Overexpression of Sadenosyl-L-methionine synthetase increased tomato tolerance to alkali stress through polyamine metabolism. Plant Biotechnol J. 12: 694-708.

Guan L, Tayengwa R, Cheng ZM, Peer WA, Murphy AS, Zhao $M$ (2019) Auxin regulates adventitious roots formation in tomato cuttings. BMC Plant Biol. 19: 1-16.

Guerra F, Bucci C (2016) Multiple roles of the small GTPase Rab7. Cells. 5: 34-62. 
Guo Y, Xiong L, Ishitani M, Zhu JK (2002) An Arabidopsis mutation in translation elongation factor 2 causes superinduction of CBF/DREB1 transcription factor genes but blocks the induction of their downstream targets under low temperatures. P Natl Acad Sci USA. 99: 7786-7791.

Gupta SC, Sharma A, Mishra M, Mishra RK, Chowdhuri DK (2010) Heat shock proteins in toxicology: how close and how far? Life Sci. 86: 377-384.

Hartl FU, Bracher A, Hartl MH (2011) Molecular chaperones in protein folding and proteostasis. Nature. 475: 324-332.

Houben M, Van de Poel B (2019) 1-Aminocyclopropane-1Carboxylic Acid Oxidase (ACO): The enzyme that makes the plant hormone ethylene. Front Plant Sci. 10: 1-15.

Howden AJM, Preston GM (2009) Nitrilase enzymes and their role in plant-microbe interactions. Microb Biotechnol. 2: 441-451.

Hu XL, Liu RX, Li YH, Wang W, Tai FJ, Xue RL, Li CH (2010) Heat shock protein 70 regulates the abscisic acid-induced antioxidant response of maize to combined drought and heat stress. Plant Growth Regul. 60: 225-235.

Jin Z, Grotewold E, Qu W, Fu G, Zhao D (2005) Cloning and characterization of a flavanone 3-hydroxylase gene from Saussurea medusa. DNA Sequence. 16: 121-129.

Jing L, Su-sheng S, Yu-sheng Z, Wei-wei G, Guang-hui G, Huiru P, Zhong-fu N, Qi-xin S, Ying-yin Y (2013) Wheat 14-3-3 protein conferring growth retardation in Arabidopsis. J Integr Agr. 12: 209-217.

Jones JDG, Dangl JL (2006) The plant immune system. Nature. 444: 323-329.

Kasukabe Y, He L, Nada K, Misawa S, Ihara I, Tachibana S (2004) Overexpression of spermidine synthase enhances tolerance to multiple environmental stresses and upregulates the expression of various stress-regulated genes in transgenic Arabidopsis thaliana. Plant Cell Physiol. 45: 712-722.

Kaur R, Kaur N, Gupta AK (2014) Structural features, substrate specificity, kinetic properties of insect $\alpha$-amylase and specificity of plant $\alpha$-amylase inhibitors. Pestic Biochem Phys. 116: 83-93.

Kaur-Sawhney R, Tiburcio AF, Altabella T, Galston AW (2003) Polyamines in plants: An overview. J Cell Mol Biol. 2: 1-12.

Khozaei M, Fisk S, Lawson T, Gibson Y, Sulpice R, Stitt M, Lefebvre SC, Rainesa CA (2015) Overexpression of plastid transketolase in tobacco results in a thiamine auxotrophic phenotype. The Plant Cell. 27: 432-447.

Lanteri ML, Laxalt AM, Lamattina L (2008) Nitric oxide triggers phosphatidic acid accumulation via phospholipase $D$ during auxin-induced adventitious root formation in cucumber. Plant Physiol. 147: 188-198.

Lee JH, Kwak G, Lim YP, Oh MH (2020) 14-3-3 proteins contribute to leaf and root development via brassinosteroid insensitive 1 in Arabidopsis thaliana. Genes Genom. 42: 347-354.

Lee Y-T, Ta HT, Duggleby RG (2005) Cyclopropane-1,1dicarboxylate is a slow-, tight-binding inhibitor of rice ketolacid reductoisomerase. Plant Sci. 168: 1035-1040.

Li H, Liu SS, Yi CY, Wang F, Zhou J, Xia XJ, Shi K, Zhou YH, Yu JQ (2014) Hydrogen peroxide mediates abscisic acid-induced HSP70 accumulation and heat tolerance in grafted cucumber plants. Plant Cell Environ. 37: 2768-2780.

Lucheta AR, Silva-Pinhati AC, Basílio-Palmieri AC, Berger IJ, Freitas-Astúa J, Cristofani M (2007) An in silico analysis of the key genes involved in flavonoid biosynthesis in Citrus sinensis. Genet Mol Biol. 30: 819-831.
Luján R, Lledías F, Martínez LM, Barreto R, Cassab GI, NietoSotelo J (2009) Small heat-shock proteins and leaf cooling capacity account for the unusual heat tolerance of the central spike leaves in Agave tequilana var. Weberpce. Plant Cell Environ. 32: 1791-1803.

Malinova I, Kunz HH, Alseekh S, Herbst K, Fernie AR, Gierth M, Fettke J (2014) Reduction of the cytosolic phosphoglucomutase in Arabidopsis reveals impact on plant growth, seed and root development, and carbohydrate partitioning. PLOS ONE. 9: 1-11.

Manhães CMC, Garcia RF, Francelino FMA, Francelino HO, Coelho FC (2015) Factors that affect sprouting and tillering of sugar cane. Vértices. 17: 163-191.

Maranho RC, Benez MM, Maranho GB, Fernandes VNA, Gonela A, Mangolin CA, Machado MFPS (2018) Extraction of total protein from axillary buds of sugarcane (Saccharum spp.) for proteomics analysis. Sugar Tech. 20: 95-99.

Maranho RC, Benez MM, Maranho GB, Neiverth A, Santos MF, Carvalho ALO, Gonela A, Mangolin CA, Machado MFPS (2019) Proteomic analysis of axillary buds of sugarcane at different cutting stages: evidence for alterations in axillary bud gene expression. Crop Pasture Sci. 70: 622-633.

Marino D, Peeters N, Rivas S (2012) Ubiquitination during plant immune signaling. Plant Physiol. 160: 15-27.

Ming R, Moore PH, Wu KK, D'hont A, Glasmann JC, Tew TL (2006) Sugarcane improvement through breeding and biotechnology. Plant Breed Rev. 27: 15-118.

Miyashita Y, Dolferus R, Ismond KP, Good AG (2007) Alanine aminotransferase catalyses the breakdown of alanine after hypoxia in Arabidopsis thaliana. Plant J. 49: 1108-1121.

Moore PH, Botha FC (2014) Sugarcane: physiology, biochemistry, and functional biology. John Wiley \& Sons, Inc: lowa: USA, p 693.

Moreno JI, Martin R, Castresana C (2005) Arabidopsis SHMT1, a serine hydroxymethyltransferase that functions in the photorespiratory pathway influences resistance to biotic and abiotic stress. Plant J. 41: 451-463.

Morimoto RI, Jurivich DA, Kroger PE, Mathur SK, Murphy SP, Nakai A, Sarge AK, Abravaya K, Sistonen LT (1994) Regulation of heat shock gene transcription by a family of heat shock factors. In: Morimoto RI, Tissieres A, Georgopoulous C (eds.) The biology of heat shock proteins and molecular chaperones. Cold Spring Harbor Press, Cold Spring Harbor.

Nahm MY, Kim SW, Yun D, Lee SY, Cho MJ, Bahk JD (2003) Molecular and biochemical analyses of OsRab7, a rice Rab7 homolog. Plant Cell Physiol. 44: 1341-1349.

Nover L, Scharf KD, Gagliard D, Vergne P, Czarnecka E, Verner WB (1996) The hsf world: classification and properties of plant heat stress transcription factors. Cell Stress Chaperon. 1: 215-223.

O'Reilly C, Turner PD (2003) The nitrilase family of CN hydrolysing enzymes - a comparative study. J Appl Microbiol. 95: 1161-1174.

Ohbayashi I, Huang S, Fukaki H, Song X, Sun S, Morita MT, Tasaka M, Millar AH, Furutani M (2019) Mitochondrial pyruvate dehydrogenase contributes to auxin-regulated organ development. Plant Physiol. 180: 896-909.

Okamoto H, Futai M (2018) Vacuolar-type ATPases in animal and plant cells. In: Roberts GCK (ed) Encyclopedia of Biophysics. European Biophysical Societies. Springer, Berlin, Heidelberg.

Pál M, Tajti J, Szalai G, Peeva V, Végh B, Janda T (2018) Interaction of polyamines, abscisic acid and proline under 
osmotic stress in the leaves of wheat plants. Sci Rep-UK. 8: Article 12839

Palmieri MC, Lindermayr C, Bauwe H, Steinhauser C, Durner J (2010) Regulation of plant glycine decarboxylase by Snitrosylation and glutathionylation. Plant Physiol. 152: 1514-1528.

Pandey S (2016) Phospholipases as GTPase activity accelerating proteins (GAPs) in plants. Plant Signal Behav. 11: e1176821.

Park CJ, Seo YS (2015) Heat shock proteins: a review of the molecular chaperones for plant immunity. Plant Pathology J. 31: 323-333.

Parsell DA, Lindquist S (1994) Heat shock proteins and stress tolerance. In: Morimoto RI, Tisslères A, Georgopoulos C (Eds.) The biology of heat shock proteins and molecular chaperones. Cold Spring Harbor Press, Cold Spring Harbor.

Piotrowski M, Schönfelder S, Weiler EW (2001) The Arabidopsis thaliana isogene NIT4 and its orthologs in tobacco encode ß-cyano-L-alanine hydratase/nitrilase. J Biol Chem. 276: 2616-2621.

Plucknett DL, Evenson JP, Sanford WG (1970) Ratoon Cropping. Adv Agron. 22: 285-330.

Pobre KFR, Poet XGJ, Hendershot LM (2019) The endoplasmic reticulum (ER) chaperone $\mathrm{BiP}$ is a master regulator of $E R$ functions: Getting by with a little help from ERdj friends. J Biol Chem. 294: 2098-2108.

Porta H, Rocha-Sosa M (2002) Plant lipoxygenases. Physiological and molecular features. Plant Physiol. 130: 1521.

Pua E-C, Chandramouli S, Han P, Liu P (2003) Malate synthase gene expression during fruit ripening of Cavendish banana (Musa acuminata cv. Williams). J Exp Bot. 54: 309-316.

Reis PAB, Rosado GL, Silva LA, Oliveira LC, Oliveira LB, Costa MD, Alvim FC (2011) The binding protein BiP attenuates stress-induced cell death in soybean via modulation of the $\mathrm{N}$-rich protein-mediated signaling pathway. Plant Physiol. 157: $1853-1865$.

Ricoult C, Echeverria LO, Cliquet JB, Limami AM (2006) Characterization of alanine aminotransferase (AlaAT) multigene family and hypoxic response in young seedlings of the model legume Medicago truncatula. J Exp Bot. 57: 3079-3089.

Riggs JW, Cavales PC, Chapiro SM, Callis J (2017) Identification and biochemical characterization of the fructokinase gene family in Arabidopsis thaliana. BMC Plant Biol. 17: 83-110.

Sáez-Vásquez J, Delseny M (2019) Ribosome biogenesis in plants: from functional $45 \mathrm{~S}$ ribosomal DNA organization to ribosome assembly factors. Plant Cell. 31: 1945-1967.

Saito-Nakano Y, Mitra BN, Nakada-Tsukui K, Sato D, Nozaki T (2007) Two Rab7 isotypes, EhRab7A and EhRab7B, play distinct roles in biogenesis of lysosomes and phagosomes in the enteric protozoan parasite Entamoeba histolytica. Cell Microbiol. 9: 1796-1808.

Santos F, Borém A (2013) Cana-de-açúcar: do plantio à colheita. Universidade Federal de Vicosa, Viçosa, Minas Gerais, p 257.

Sekula B, Dauter Z (2019) Spermidine synthase (SPDS) undergoes concerted structural rearrangements upon ligand binding - A case study of the two SPDS isoforms from Arabidopsis thaliana. Front Plant Sci. 10: Article 555.

Shetty NP, Jensen JD, Knudsen A, Finnie C, Geshi N, Blennow A, Collinge DB, Jørgensen HJL (2009) Effects of $\beta$-1,3-glucan from Septoria tritici on structural defence responses in wheat. J Exp Bot. 60: 4287-4300.
Shi H, He S, He X, Lu S, Guo Z (2019) An eukaryotic elongation factor 2 from Medicago falcata (MfEF2) confers cold tolerance. BMC Plant Biol. 19: 218-231.

Smith DM, Inman-Bamber NG, Thorburn PJ (2005) Growth and function of the sugarcane root system. Field Crop Res. 92: 169-183.

Spaull VW (1990) Preliminary observations on the rooting habit of some sugarcane varieties in South Africa. Proc South African Sugar Technol Assoc. 54: 177-180.

Stein O, Granot D (2018) Plant fructokinases: evolutionary, developmental, and metabolic aspects in sink tissues. Front Plant Sci. 9: Article 339.

Szklarczyk D, Gable AL, Lyon D, Junge A, Wyder S, HuertaCepas J, Simonovic M, Doncheva NT, Morris JH, Bork P, Jensen LJ, von Mering C (2019) STRING v11: protein-protein association networks with increased coverage, supporting functional discovery in genome-wide experimental datasets. Nucleic Acids Res. 47: D607-613.

Takác T, Novák D, Samaj J (2019) Recent advances in the cellular and developmental biology of phospholipases in plants. Front Plant Sci. 10: 1-12.

Timm S, Wittmi M, Gamlien S, Ewald R, Florian A, Frank M, Wirtz M, Hell R, Fernie AR, Bauwea H (2015) Mitochondrial dihydrolipoyl dehydrogenase activity shapes photosynthesis and photorespiration of Arabidopsis thaliana. Plant Cell. 27: 1968-1984.

Toei M, Saum R, Forgac M (2010) Regulation and isoform function of the V-ATPases. Biochemistry-US. 49: 4715-4723.

Trivedi DK, Gill SS, Yadav S, Tuteja N (2013) Genome-wide analysis of glutathione reductase (GR) genes from rice and Arabidopsis. Plant Sign Behav. 8: e23201.

Üstün S, Sheikh A, Gimenez-Ibanez $S$, Jones A, Ntoukakis V, Börnke $F(2016)$ The proteasome acts as a hub for plant immunity and is targeted by Pseudomonas type III effectors. Plant Physiol. 172: 1941-1958.

Valente MAS, Faria JAQA, Soares-Ramos JRL, Reis PAB, Pinheiro GL, Piovesan ND, Morais AT, Menezes CC, Cano $M A O$, Fietto LG, Loureiro ME, Aragão FJL, Fontes EPB (2009) The ER luminal binding protein (BiP) mediates an increase in drought tolerance in soybean and delays droughtinduced leaf senescence in soybean and tobacco. J Exp Bot. 60: 533-546.

Van de Poel B, Smet D, Van Der Straeten D (2015) Ethylene and hormonal cross talk in vegetative growth and development. Plant Physiol. 169: 61-72.

Van Dillewijn C (1952) Botany of sugarcane. The Chronica Botanica Co. Waltham.

Verna AK, Tamadaddi C, Tak Y, Lal SS, Cole SJ, Hines JK, Sahi C (2019) The expanding world of plant J-domain proteins. Crit Rev Plant Sci. 38: 382-400.

Vieira OV, Bucci C, Harrison RE, Trimble WS, Lanzetti L, Gruenberg J, Schreiber AD, Stahl PD, Grinstein S (2003) Modulation of Rab5 and Rab7 recruitment to phagosomes by phosphatidylinositol 3-kinase. Mol Cell Biol. 23: 25012514.

Villén J, Gygi SP (2008) The SCX/IMAC enrichment approach for global phosphorylation analysis by mass spectrometry. Nat Protoc. 3: 1630-1638.

Wang B, Wang G, Shen F, Zhu S (2018) A glycine-rich RNAbinding protein, CsGR-RBP3, is involved in defense responses against cold stress in harvested cucumber (Cucumis sativus L.) fruit. Front Plant Sci. 9: Article 540.

Wang D, Weaver ND, Kesarwani M, Dong X (2005) Induction of protein secretory pathway is required for systemic acquired resistance. Science. 308: 1036-1040. 
Wang X (2000) Multiple forms of phospholipase D in plants: the gene family, catalytic and regulatory properties, and cellular functions. Prog Lipid Res. 39: 109-149.

Wang XQ, He XZ, Lin JQ, Shao H, Chang ZZ, Dixon RA (2006) Crystal structure of isoflavone reductase from alfalfa (Medicago sativa L.). J Mol Biol. 358: 1341-1352.

Wilke DE, Otto JJ (2003) Profilin functions in cytokinesis, nuclear positioning, and stomatogenesis in Tetrahymena thermophila. J Eukaryot Microbiol. 50: 252-262.
Xu Z, Ma J, Qu C, Hu Y, Hao B, Sun Y, Liu Z, Yang H, Yang C, Wang H, Li Y, Liu G (2017) Identification and expression. analyses of the alanine aminotransferase (AlaAT) gene family in poplar seedlings. Sci Rep-UK. 7: Article 45933.

Zhao Q, Liu C (2018) Chloroplast chaperonin: An intricate protein folding machine for photosynthesis. Front $\mathrm{Mol}$ Biosci. 4: Article 98. 